\title{
Comparison of the Epidemiologic Features and Patterns of Initial Care for Prostate Cancer between Public and Private Institutions: A Survey by the Brazilian Society of Urology
}

Aguinaldo Cesar Nardi, Rodolfo Borges dos Reis, Stenio de Cassio Zequi, Arquimedes Nardozza Junior

Sociedade Brasileira de Urologia, Section Sao Paulo

\section{ABSTRACT}

Objective: To describe the epidemiological features and patterns of initial care for prostate cancer at public and private institutions in the State of Sao Paulo, Brazil. Materials and Methods: A total of 1,082 physicians affiliated to the Sao Paulo Section of the Brazilian Society of Urology were invited to participate in this cross-sectional, web-based survey. Between September 2004 and September 2005, participating urologists entered data on demographic, clinical and pathological characteristics of patients diagnosed with prostate cancer in their practice. Data on patients attended at public institutions were analyzed and compared with those patients attended at private practice.

Results: One hundred and ten society members contributed with data from 1915 patients, 1026 (53.6\%) of whom from public institutions. When compared with patients attended at private institutions, those attended at public institutions were older and more likely to be black, had higher serum prostate specific antigen (PSA) levels, had a higher probability of being diagnosed with metastatic disease, but were less likely to undergo prostatectomy (all $\mathrm{P}<0.001$ ). In multivariate analysis, age, biopsy Gleason score, and being attended at a public institution were independently associated with metastatic disease upon diagnosis. The significant predictors of nonsurgical treatment were age, black race, and higher serum levels of PSA.

Conclusions: A statewide registry provides valuable information regarding patient demographics, clinical features, and patterns of care. The results of this study suggest that significant disparities exist for patients with prostate cancer attended at different health-care systems. The relative contribution of biological versus socioeconomic features remains uncertain.

\section{ARTICLE INFO}

\section{Key words:}

Cross-sectional studies; epidemiology; prostatic neoplasms; insurance; health

Int Braz J Urol. 2012; 38: 155-66

Submitted for publication:

August 05, 2011

Accepted after revision: October 24, 2011

\section{INTRODUCTION}

Prostate cancer is one of the leading neoplasms in the male population worldwide (1); it is currently the most frequent tumor type in
Brazil, where an estimated 52,000 new cases are diagnosed each year (2). With nearly $21 \%$ of the country population (3), the State of Sao Paulo contributes with an estimated 13.160 annual cases of prostate cancer, or nearly $25 \%$ of all new cases 
of this disease in Brazil (2). In the State of Sao Paulo, approximately 38\% of the population had access to private health insurance in 2003, and $40 \%$ in 2008 (4). Accordingly, an estimated 37\% of patients with prostate cancer in the State of Sao Paulo received medical care under coverage by private insurance companies (5). The vast majority of the remaining individuals not covered by private insurance receive medical care through the public health-care system, whose hierarchical structure dictates patient referrals to more complex health organizations in geographically defined areas.

Since prostate cancer accounts for a sizeable proportion of the workload of many urologists, many of whom base their practice in publicly-funded organizations, the Brazilian Society of Urology (Sociedade Brasileira de Urologia, SBU) committed to undertake a statewide survey, whose overall results have been published (5). The aim of that survey was to describe the demographic, clinical, and pathological characteristics, as well as the patterns of initial care, for patients with prostate cancer diagnosed and treated by members of SBU in the State of Sao Paulo. In the current analysis, the aim was to compare in detail such features among patients treated at public and private institutions in the State of Sao Paulo during the study period.

\section{MATERIALS AND METHODS}

\section{Overall study design}

In this cross-sectional study, a web-based survey was conducted with 1,082 SBU members from the State of Sao Paulo, who were invited to participate in the study through mailed announcements and advertising of the study on the SBU website (www.sbu.org.br). The questionnaire used in the survey was available at the website for the duration of the study, and could also be sent by regular mail or fax upon request. In addition, supplementary information and reminders were regularly sent by regular mail and e-mail to all SBU members in the State of Sao Paulo. The study protocol was approved by three academic institutional review boards (IRBs) and by the State Health Secretariat, and all participating patients signed an informed consent document. Protocol submission to local IRBs was left to the discretion of investigators according to local policies.

\section{Data collection}

Participating physicians were asked to collect data from patients with prostate cancer seeking medical attention at public or private practices between September 2004 and September 2005. The questionnaire contained 23 questions related to characteristics of the participating physician, demographic and socioeconomic patient features, and clinical and pathological aspects of prostate cancer. Special attention was given to the flow of patient care, and places of residence, diagnosis and care were ascertained from each case. For staging purposes, the 2002 International Union Against Cancer/Tumor Node Metastasis (TNM) classification system was used (6). All filled questionnaires were kept for final analysis in a central database that was maintained under the supervision of SBU, whose scientific committee vouched for the data presented herein.

\section{Statistical analysis}

Descriptive statistics were used for the demographic, clinical, and pathological variables. Exploratory analyses were conducted for comparisons between groups of patients according to medical or socioeconomic features of interest. The chi-square test was used to compare the frequency of categorical variables between groups, and the Mann-Whitney test was used to compare continuous variables with non-normal distribution. Logistic regression models were used to explore the associations between selected potential risk factors and categorical outcomes. All P values were two sided, and P < 0.05 was considered significant. All data analysis was conducted using the MedCalc software, version 11.0.0.0 (MedCalc, Mariakerke, Belgium).

\section{RESULTS}

Physician and patient characteristics

One hundred and ten of the 1,082 (10.2\%) registered SBU members contributed with data from a total of 1915 patients, an average of 17.4 
patients per urologist over the 1-year period. Participating urologists had an average of 44 years of age (range, 26 to 74). Among the patients included in the study, 1,026 (53.6\%) had been attended at public institutions. Table- 1 shows the chief demo- when black patients were compared with those of other races (15.4\% versus $12.8 \%$, respectively; $\mathrm{P}$ $=0.394)$. However, black patients had higher serum levels of PSA than white and Asian patients (median of 12.5 versus $9.6 \mathrm{ng} / \mathrm{mL} ; \mathrm{P}=0.001$ ).

Table 1 - Demographic characteristics of patients attended at public institutions.

\begin{tabular}{lcc}
\hline Characteristic & Number & Percent \\
\hline Age, years & $68( \pm 8), 36$ to 95 & \\
$\quad$ Mean $( \pm S D)$, range & & \\
Race & & \\
White & 828 & 80.7 \\
Black & 188 & 18.3 \\
Asian & 10 & 1.0 \\
Family history of prostate cancer & & 71.8 \\
No & 737 & 8.4 \\
One case & 86 & 1.5 \\
Two or more cases & 15 & 18.3 \\
Unknown & 188 & \\
\hline
\end{tabular}

SD: Standard Deviation.

graphic characteristics of these patients. Their mean age was 68 years (range, 36 to 95), nearly 80\% of patients were reportedly white, and approximately $70 \%$ had no family history of prostate cancer.

\section{Disease characteristics}

The clinical characteristics of patients attended at public institutions are shown in Table-2. The serum level of prostate specific antigen (PSA) upon diagnosis was available for 976 patients $(95.1 \%)$; the median value was $10.0 \mathrm{ng} / \mathrm{mL}$, ranging from 0.1 to $2890.0 \mathrm{ng} / \mathrm{mL}$. The biopsy Gleason score was not known for nine patients (0.9\%). In the remaining cases, the most frequent scores were 5 or $6(51.8 \%)$, followed by $7(32.1 \%)$; only $13.3 \%$ of patients had a Gleason score of 8 to 10 . There was no significant difference in the percentage of patients with a Gleason score of 8 to 10 ,
Regarding the anatomic disease stage, slightly over two-thirds of patients had localized disease, $20.2 \%$ had locally advanced disease, and 10.4\% had metastatic disease (Table-2). Among patients with metastatic disease, the most frequent primary sites of metastases were the bones (65.4\%).

\section{Patterns of initial care}

Figure-1 displays the treatment modalities recommended for patients attended at public institutions. Surgery was the most frequent modality and was recommended for 485 patients (47.3\%). Of these patients, $321(66.2 \%)$ were recommended to undergo retropubic prostatectomy, 161 (33.2\%) perineal prostatectomy, and only three were referred to laparoscopic surgery. Radiotherapy with or without hormone therapy was the recommendation in 278 cases $(27.1 \%)$, orchiectomy or oth- 
Table 2 - Clinical characteristics of patients attended at public institutions.

\begin{tabular}{|c|c|c|c|}
\hline Characteristic & & Number & Percent \\
\hline \multicolumn{4}{|l|}{ PSA, ng/mL } \\
\hline Median (IQR), range & 10.0 (6.4 to 23.0 ), 0.1 to 2890.0 & & \\
\hline Mean $( \pm$ SD) & $36.7( \pm 143.3)$ & & \\
\hline \multicolumn{4}{|l|}{ Gleason score } \\
\hline 2 to 4 & & 21 & 2.0 \\
\hline 5 or 6 & & 531 & 51.8 \\
\hline 7 & & 329 & 32.1 \\
\hline 8 to 10 & & 136 & 13.3 \\
\hline Unknown & & 9 & 0.9 \\
\hline \multicolumn{4}{|l|}{ Disease stage } \\
\hline Localized & & 712 & 69.4 \\
\hline Locally advanced & & 207 & 20.2 \\
\hline Metastatic & & 107 & 10.4 \\
\hline
\end{tabular}

IQR: Interquartile Rrange; PSA: Prostate Specific Antigen.

Figure 1 - Initial treatment modality recommended for patients attended at public institutions $(\mathrm{N}=\mathbf{1 0 2 6})$.

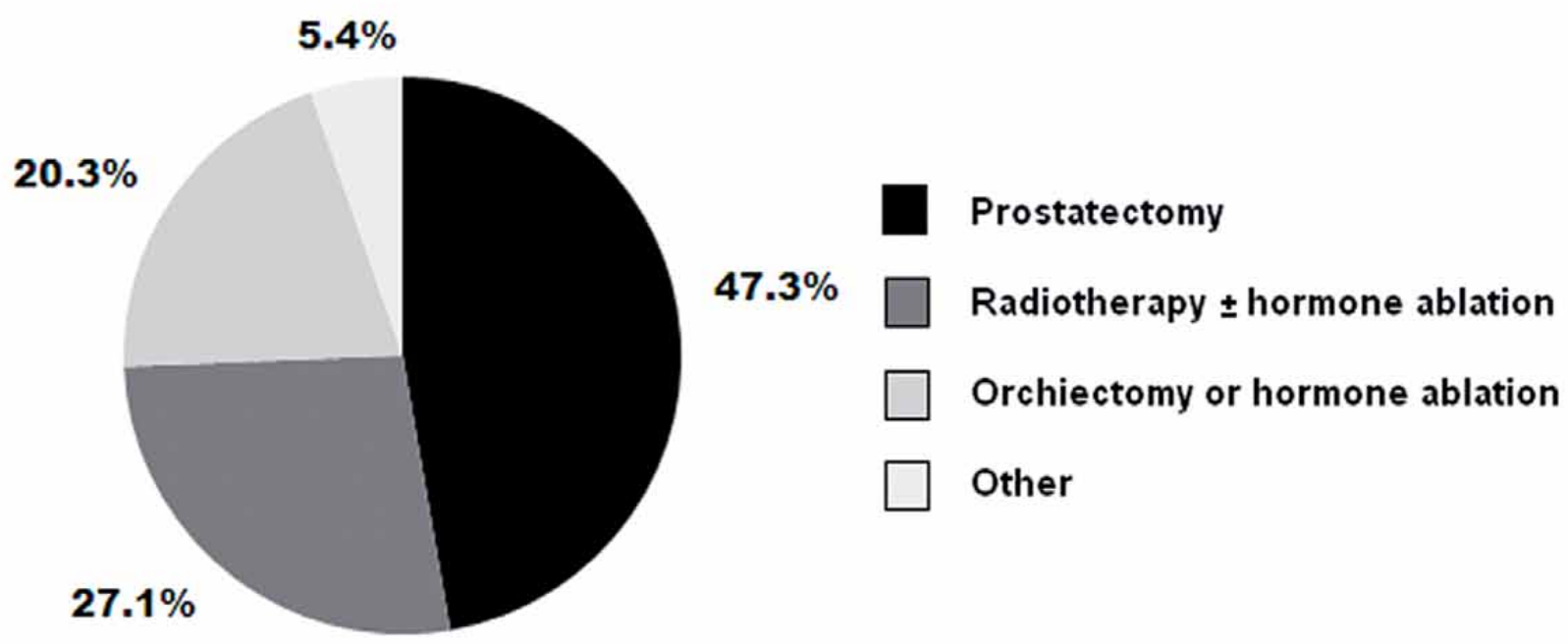


er types of hormone ablation alone in 208 cases $(20.2 \%)$, and palliative care or other modalities were recommended for only 55 cases (5.4\%).

\section{institutions \\ Comparisons between public and private \\ When compared with patients attended} at private institutions $(\mathrm{N}=889)$, those attended at public institutions were slightly older (median ages of 67 versus 69 years; $\mathrm{P}<0.001$ ) and more likely to be black $(7.0 \%$ versus $18.3 \%$; $\mathrm{P}<0.001)$. Patients attended at public institutions had a higher median value of PSA (10.0 versus $6.8 \mathrm{ng} /$ $\mathrm{mL} ; \mathrm{P}<0.001)$ and a higher probability of being diagnosed with metastatic disease $(10.4 \%$ versus $4.2 \% ; \mathrm{P}<0.001$ ) than patients attended at private institutions. As shown in Table-3, adjustment for age, black race and Gleason score disclosed that being attended at a public institution was independently associated with metastatic disease upon diagnosis when the total sample of 1915 patients was considered. Other independent variables for the presence of metastatic disease upon diagnosis were age and biopsy Gleason score. In addition, patients attended at public institutions were significantly less likely to undergo prostatectomy than patients attended at private institutions (47.3\% versus 61.3\%; $\mathrm{P}<0.001$ ). However, after adjusting for age, race, serum PSA upon diagnosis, and Gleason score, being attended at a public institution was not associated with treatment modalities other than prostatectomy. The only significant predictors of such modalities (i.e., no prostatectomy) were age, black race and higher serum levels of PSA considered as a continuous variable (Table-4). Similar results were observed when the analysis was restricted to patients with no metastatic disease at diagnosis (data not shown). Finally, patients attended at public and private institutions were compared regarding the

Table 3 - Multivariate analysis of factors associated with metastatic disease upon diagnosis in the total sample of 1915 patients.

\begin{tabular}{lcc}
\hline Variable & Multivariate OR (95\% Cl) & P value \\
\hline Age & $1.03(1.01$ to 1.06$)$ & 0.002 \\
Black race & $1.09(0.67$ to 1.78$)$ & 0.718 \\
Gleason score & $1.19(1.15$ to 1.25$)$ & $<0.001$ \\
Diagnosis at public institution & $2.38(1.59$ to 3.56$)$ & $<0.001$ \\
\hline
\end{tabular}

Cl: confidence interval; OR: odds ratio.

Table 4 - Multivariate analysis of factors associated with prostatectomy as initial treatment in the total sample of 1915 patients.

\begin{tabular}{|c|c|c|}
\hline Variable & Multivariate OR $(95 \% \mathrm{Cl})$ & $P$ value \\
\hline Age & 0.88 (0.86 to 0.89$)$ & $<0.001$ \\
\hline Black race & 0.57 (0.40 to 0.81$)$ & 0.002 \\
\hline Serum PSA & 0.95 (0.94 to 0.96$)$ & $<0.001$ \\
\hline Gleason score & 0.99 (0.96 to 1.02$)$ & 0.773 \\
\hline Diagnosis at public institution & $0.84(0.67$ to 1.05$)$ & 0.127 \\
\hline
\end{tabular}

CI: confidence interval; OR: odds ratio; PSA: Prostate Specific Antigen 
need of displacement from the city of residence to another city to be diagnosed or receive care. For this analysis, patients attended at private institutions were divided into two groups based on whether they have used or not a health insurance; nine patients attended at private institutions had no available information on the use of a health insurance and were excluded from this specific analysis. As shown in Figure-2, patients attended at private institutions with no health insurance were more likely to dislocate from the city of residence $(126 / 172 ; 73.3 \%)$, followed by patients attended at public institutions $(705 / 1026 ; 68.7 \%)$ and patients attended at private institutions using a health insurance $(266 / 708 ; 37.6 \%)$. There was a significant difference between the three groups regarding the need of displacement $(\mathrm{P}<0.0001)$, with patients using a health insurance being significantly less likely to have to dislocate.

\section{DISCUSSION}

The current study represents an effort to characterize the demographic and clinical features, as well as the patterns of care for patients with prostate cancer attended at public and private institutions in the State of Sao Paulo, Brazil.
During the study period, data were collected on 1,915 patients, a figure that corresponds to $16 \%$ of all cases estimated by the Brazilian National Cancer Institute for that State in 2005 (7). Of those cases, 53.6\% were attended at public institutions, a percentage that conforms to the proportion of the population in the State of Sao Paulo with no coverage by private insurance companies (4). Therefore, it is likely that the data presented herein are representative of the whole population of patients with prostate cancer in the State of Sao Paulo, Brazil. On the other hand, it is possible that the method of data collection and the profile of the urologists that decided to participate in the study may have introduced unknown biases. However, there is not a priori reason to believe that such biases are present in the study. Moreover, to our knowledge, this study represents the one with the highest number of participating urologists contributing with data in the state of Sao Paulo, Brazil.

Overall, the data presented herein support the notion that patients attended at public institutions are slightly older and more likely to be black, and have higher levels of PSA and a higher probability of being diagnosed with metastatic disease than patients attended at private institutions. In addition, patients attended at public institutions

Figure 2 - Need of displacement from the city of residence, according to the health-care system.

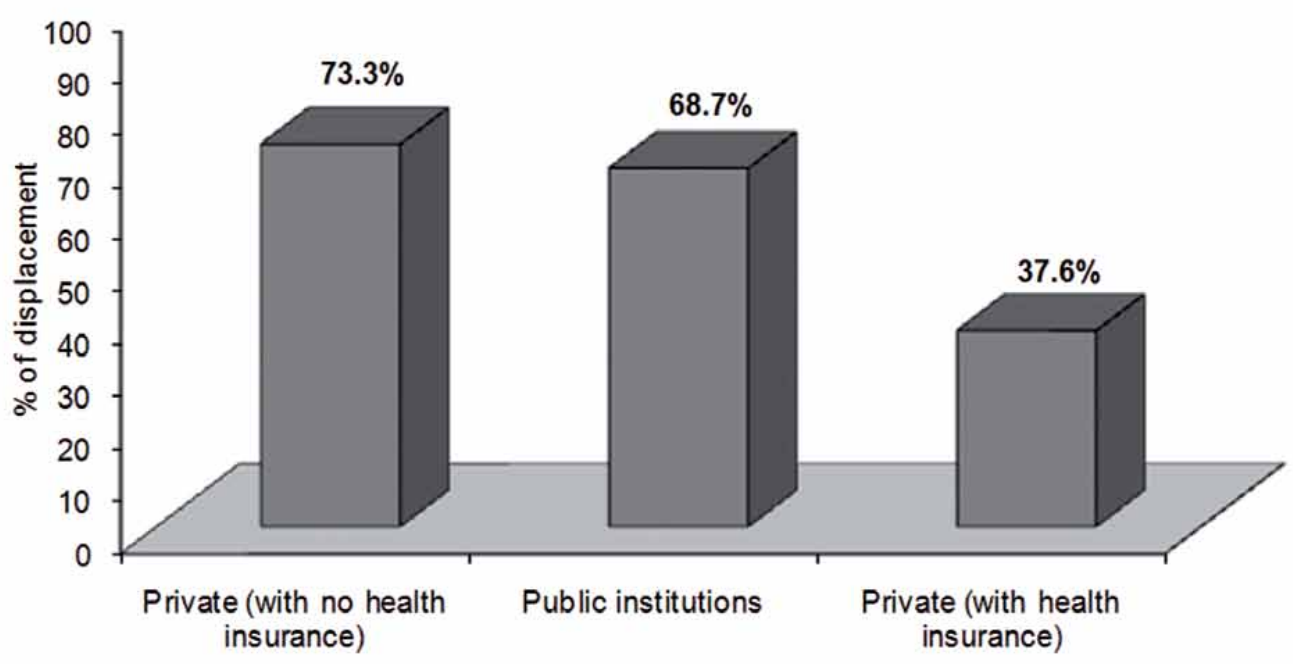


appear to be significantly more likely to undergo treatment modalities other than prostatectomy, possibly as a result of demographic and clinical characteristics, such as the older age and the higher serum levels of PSA in public institutions, when compared with private institutions.

The biological differences in prostate cancer between black and non-black patients have been highlighted in the literature for several decades (8). The incidence and mortality rates for prostate cancer are higher in blacks and AfricanAmericans than in other ethnic groups (9). When adjusted for other biological disease features, PSA levels are higher in blacks and African-Americans than in other groups, regardless of socioeconomic factors (10-13). In the United States, black patients were more likely to receive nonsurgical treatment for prostate cancer $(14,15)$. In agreement with these findings, in the current study, black individuals had higher serum levels of PSA than whites and Asians, and black race was associated with the use of treatment modalities other than prostatectomy. On the other hand, no association was found between race and the percentage of patients with biopsy Gleason scores of 8 to 10, and black race was not identified as an independent variable for the presence of metastatic disease upon diagnosis. Of note, contrasting findings among studies conducted in different countries may reflect distinct ancestors and, thus, genetic differences between Brazilian and North-American black population. In this regard, it is known that the Bantu haplotype predominates in Brazil, as the Brazilian black population is mostly originated from Angola, Congo and Mozambique, while other haplotypes predominate in the North American black population $(16,17)$. In addition, countries differ regarding the degree of miscegenation. As recently published by the Instituto Brasileiro de Geografia Estatística (IBGE), in Brazil, black race is associated with lower annual and familiar income, lower educational level as well as access to health assistance, when compared with other races (18), factors that probably contribute with the unfavorable kind of disease presentation in this group.

Since patients attended at public institutions were more likely to be older and present higher PSA levels, these factors may have contrib- uted to the lower frequency of prostatectomy observed for patients attended at these institutions. Furthermore, patients treated at reference public hospitals, most of the time, are referred from different areas and in many times the treatment is postponed after the diagnosis. In this regard, we found that displacement from the city of residence to another city in order to seek for diagnosis and care was more frequently required among patients attended at public institutions or at private institutions with no health insurance than in the group of patients attended at private institutions, but with health insurance. Although similar rates of dislocation were observed for patients attended at public institutions and those attended at private institutions with no health insurance, reasons for dislocation probably differed between these two groups, although not accessed in this study. Patients attended at public institution seem to dislocate to a different city as part of the patient flow that is established at the public health-care system, while patients attended at private institutions choose where they want to be treated at. Contrasting with these two groups, patients with health insurance were less likely to dislocate, what may be related to the fact that health insurance companies generally provide and obligate the complete treatment in a city not allowing patients to chose where they want to be treated. The follow up schedule (need to travel) and the perception level of patients and families regarding disease severity are other factors that may influence the decision on screening an asymptomatic patient and choose the treatment modality.

Screening can be defined as the application of diagnostic tests or procedures to asymptomatic people for the purpose of dividing them into two groups: those who have a condition that would benefit from early intervention and those who do not, other issues of equal importance include using scarce resources efficiently and rationally. It is important to recognize that the ultimate purpose of screening is to reduce morbidity and mortality. If improved outcomes cannot be demonstrated, the rationale for screening is lost. Although screening is unquestionably important, other issues of equal importance include using scarce resources efficiently and rationally. In private offices the physi- 
cian-patient relationship is crucial and can be influenced by economic factors, resources available and patient's characteristics; on the other hand, in public institutions screening polices are different from the one adopted at private institutions and not infrequently the treatment is postponed due the disparity between the number of patients requiring treatment and the scarce resources.

The debate on the association between a lower socioeconomic status and variables such as stage at diagnosis, use of less aggressive treatment, and mortality, has been ongoing in the United States and other countries for several years (19-21). Socioeconomic factors are clearly associated with the patterns of care for various tumor types, including prostate cancer $(14,19)$.

Brazil is a country with larger inequalities in socioeconomic status and more uneven access to medical care between socioeconomic groups. Three recent studies (22-24) two from the United States and one from Brazil found that prostate cancers were more commonly advanced at diagnosis and the prostate cancer mortality was higher among men with lower socioeconomic status than among those with higher socioeconomic status. Therefore, it is possible that differences in patterns of care between public institutions and private institutions in Sao Paulo State are due to a set of factors such as discrepant local screening polices, tumor biological behavior, socioeconomic status and geographic differences, among patients attended at these two types of health-care system $(25,26)$.

In the United States, regional differences have been found in how physicians and patients select treatment options $(15,27)$. The results of the current study should not be extrapolated to Brazil as a whole, because cultural differences, screening polices, public and private health systems and treatment resources availability may vary across the country.

\section{CONCLUSIONS}

The results presented herein confirm that statewide registry of prostate cancer is feasible and provides valuable information regarding patient demographics, clinical features, and patterns of care, analogously to national studies previously conducted by SBU in other disease settings $(28,29)$. The results of this study suggest that significant disparities exist for patients with prostate cancer attended at public and private institutions, but the relative contribution of biological versus socioeconomic features remains uncertain at present. Further studies with longer follow-up are necessary to assess the impact in quality of life and prostate cancer mortality in patients attended at public and private institutions.

\section{ACKNOWLEDGEMENTS}

We would like to thank Dr. Djalma de Carvalho Moreira Filho for his fundamental contribution to the statistical analysis.

This project was possible due to a Novartis educational grant.

We would like to thanks to all the urologists who made this project possible: Aguinaldo Cesar Nardi, Alexandre Gomes Agostinho, Alfredo Costa Lima Valente Júnior, Ali Mohamed Kassn Awada, Alvaro Sadek Sarkis, Andre Pereira Vanni, Antonio Fonseca, Antonio Laercio Botasso, Antonio Matheus Rodrigues, Antonio Pádua Leal Galesso, Antonio Rubens Lima de Castro, Beatriz Helena de Paula Cabral, Carlos Alberto Bezerra, Carlos Benedito Menezes Verona, Carlos Hermann Schaal, Cassio Luis Zanettini Riccetto, Celso Augusto Saad Abujamra, Celso de Oliveira, Cesar Augusto Bortoluzo, Cesar Geraldo Benemond, Cesar Nardy Zillo, Claudio Jose Pagotto, Darci Schiavon de Abreu, Demerval Mattos Junior, Douglas Otto Verndl, Edmilson de Oliveira, Eduardo Herreros, Elcio Dias Silva, Elzio Ramos Mariottoni, Enio Ferreira Freitas, Fabio Alexandre Pardal, Fabio Gustavo Oliveira, Fabio Mendes Engler, Fernando Cesar Sala, Fernando Donizete da Cunha, Fernando Nestor Facio Júnior, Flavio Fioravanti Azank, Flavio Soares Magalhães, Francesco Caporrino, Francisco Aurilio de Melo Castro, Francisco Barros de Oliveira, Francisco Paulo da Fonseca, Geovanne Furtado Souza, Geraldo Eduardo de Faria, Geraldo Ferreira Borges Júnior, Gilberto Fava, Gilberto Saber, Guilherme Godoy, Gustavo Affonso Ferreira, Gustavo Caserta Lemos, Hamilton de Campos 
Zampolli, Hamilton Jose Borges, Hamilton Veloso da Costa, Helio Begliomini, Joao Afif Abdo, Joao Moreira Pinto, Joao Reinaldo de Oliveira Abrao, Joao Sergio de Carvalho Filho, Joao Yasuki Yamamoto, Jose Carlos Melo Novaes, Jose do Carmo Gaspar Sartori, Jose Luiz Borges de Mesquita, Jose Moises Terrazas Garret, Jose Roberto Santos, Juan Carlos T Arroniz, Jurandir Yoshito Hayashi, Kleber Eduardo Piedade, Leonardo Xavier Moreira, Luciano Almeida de Matos, Luis Cesar Fava Spessotto, Luis Eduardo Murgel de Castro Santos, Luiz Figueiredo Mello, Luiz Henrique Machado, Luiz Renato Montez Guidoni, Lycurgo de Castro Santos Neto, Marcelo de Paula Galesso, Marcelo Silva Watanabe, Marco Antonio Arap, Marco Antonio Fioravante, Marjo Deninson Cardenuto Perez, Mauricio J Bruschini Rodrigues Netto, Miguel Zerati Filho, Nelson Rodrigues Netto Júnior, Norio Ikari, Pedro Assaf Junior, Pedro Luiz Macedo Cortado, Reinaldo Sacco, Renato Chavasco de Souza, Renato Panhoca, Renato Prado Costa, Ricardo Ferri Barreto, Ricardo Reges Maia, Ricardo Ribeiro Peixinho, Roberto Benedito Quaioti, Roberto Rocha Brito Bresler, Rodrigo Luvizotto, Rodrigo Ribeiro Cortez, Ronaldo de Aguiar S. Zulian, Rubens Carlos Martucci, Rubens Luiz Villela, Rui Nogueira Barbosa, Sander de Cassio Zequi, Sandro Mendonça de Faria, Silvio Luiz Cordeiro, Stenio de Cassio Zequi, Ubirajara Ferreira, Vicente de Paula Cirio Nogueira, Victor Augusto Sanguinetti S Leitao, Wagner Raiter José, Walter da Silva Junior.

\section{CONFLICT OF INTEREST}

None declared.

\section{REFERENCES}

1. World Health Organization. International Agency for Research on Cancer. World Cancer Report 2008. Lyon: 2008.

2. Brasil. Ministério da Saúde. Instituto Nacional de Câncer. Estimativa 2010: Incidência de Câncer no Brasil. Available at http://www.inca.gov.br/estimativa/2010/ (Accessed on 10/7/10).

3. Instituto Brasileiro de Geografia e Estatística (IBGE). Dados do Censo 2010 publicados no Diário Oficial da União do dia 04/11/2010. Available at http://www.cens02010.ibge.gov. br/dados_divulgados/index.php (Accessed 1/28/11).
4. Brasil. Ministério da Saúde. Rede Interagencial de Informações para a Saúde. Indicadores de Cobertura. Cobertura de planos de saúde. Available at http://tabnet.datasus.gov.br/ cgi/idb2009/matriz.htm (Accessed 1/27/11).

5. Nardi AC, Nardozza Jr A, Moreira Filho D de C, Rios LAS, Zequi $S$ de C: Perfil do câncer de próstata no estado de São Paulo detectado pela Sociedade Brasileira de Urologia - secção São Paulo. São Paulo: SBU, 2005.

6. Sobin LH, Wittekind $\mathrm{CH}$. TNM classification of malignant tumours. 6th ed. New York: Willey-Liss; 2002. p. 185-7.

7. Brasil. Ministério da Saúde. Instituto Nacional de Câncer. Estimativa de incidência e mortalidade por câncer no Brasil - 2005. http://www.inca.gov.br.

8. Polednak AP, Flannery JT: Black versus white racial differences in clinical stage at diagnosis and treatment of prostatic cancer in Connecticut. Cancer. 1992; 70: 2152-8.

9. Jemal A, Siegel R, Xu J, Ward E: Cancer statistics, 2010. CA Cancer J Clin. 2010; 60: 277-300. Epub 2010 Jul 7. Erratum in: CA Cancer J Clin. 2011; 61: 133-4.

10. Vijayakumar S, Karrison T, Weichselbaum RR, Chan S, Quadri SF, Awan AM: Racial differences in prostate-specific antigen levels in patients with local-regional prostate cancer. Cancer Epidemiol Biomarkers Prev. 1992; 1 : 541-5.

11. Moul JW, Sesterhenn IA, Connelly RR, Douglas T, Srivastava S, Mostofi FK, et al.: Prostate-specific antigen values at the time of prostate cancer diagnosis in African-American men. JAMA. 1995; 274: 1277-81.

12. Ndubuisi SC, Kofie VY, Andoh JY, Schwartz EM: Blackwhite differences in the stage at presentation of prostate cancer in the District of Columbia. Urology. 1995; 46: 71-7.

13. Vijayakumar S, Winter K, Sause W, Gallagher MJ, Michalski J, Roach M, et al.: Prostate-specific antigen levels are higher in African-American than in white patients in a multicenter registration study: results of RTOG 94-12. Int J Radiat Oncol Biol Phys. 1998; 40: 17-25.

14. Schwartz K, Powell IJ, Underwood W 3rd, George J, Yee C, Banerjee M: Interplay of race, socioeconomic status, and treatment on survival of patients with prostate cancer. Urology. 2009; 74: 1296-302.

15. Harlan L, Brawley O, Pommerenke F, Wali P, Kramer B: Geographic, age, and racial variation in the treatment of local/ regional carcinoma of the prostate. J Clin Oncol. 1995; 13: 93-100.

16. Zago MA, Figueiredo MS, Ogo SH: Bantu beta s cluster haplotype predominates among Brazilian blacks. Am J Phys Anthropol. 1992; 88: 295-8.

17. Paschoalin EL, Martins AC, Pastorello M, Sândis KA, Maciel LM, Silva WA Jr, et al.: Racial influence on the prevalence of prostate carcinoma in Brazilian volunteers. Int Braz J Urol. 2003; 29: 300-5. 
18. Instituto Brasileiro de Geografia e Estatística (IBGE). Síntese de Indicadores Sociais - Uma Análise das Condições de Vida da População Brasileira, 2009. Rio de Janeiro: IBGE, 2009; pp. 252.

19. Byers TE, Wolf HJ, Bauer KR, Bolick-Aldrich S, Chen VW, Finch $\mathrm{JL}$, et al.: The impact of socioeconomic status on survival after cancer in the United States: findings from the National Program of Cancer Registries Patterns of Care Study. Cancer. 2008; 113: 582-91.

20. McCredie M, Bell J, Lee A, Rogers J: Differences in patterns of care of prostate cancer, New South Wales, 1991. Aust N Z J Surg. 1996; 66: 727-30.

21. Rapiti E, Fioretta G, Schaffar R, Neyroud-Caspar I, Verkooijen HM, Schmidlin F, et al.: Impact of socioeconomic status on prostate cancer diagnosis, treatment, and prognosis. Cancer. 2009; 115: 5556-65.

22. Dall'era MA, Hosang N, Konety B, Cowan JE, Carroll PR: Sociodemographic predictors of prostate cancer risk category at diagnosis: unique patterns of significant and insignificant disease. J Urol. 2009; 181: 1622-7; discussion 1627.

23. Tewari AK, Gold HT, Demers RY, Johnson CC, Yadav R, Wagner EH, et al.: Effect of socioeconomic factors on longterm mortality in men with clinically localized prostate cancer. Urology. 2009; 73: 624-30. Erratum in: Urology. 2009; 74: 239. Yood, Marianne Ulcickas [added].

24. Srougi V, Antunes AA, Reis ST, Dall'oglio MF, Nesrallah AJ, Leite KR, et al.: Socioeconomic status is an independent predictor of biochemical recurrence among patients with prostate cancer who undergo radical prostatectomy. Int Braz J Urol. 2011; 37: 507-13.

\section{EDITORIAL COMMENT}

Limiting the rationale of its handling, the prostate cancer $(\mathrm{PCa})$ natural history is varied, often long, and not consistently predictable and in a life period in which competing causes of mortality are high and erratic.

In this complex scenario, although it is known that the only valid comparisons are in the context of randomized clinical trials, headto-head comparisons are frequent because of the paucity of adequate trials. Add to this the fact, the population-based studies in Brazil are even scarcer and very limited. Even including about
25. Amling CL, Kane CJ, Riffenburgh RH, Ward JF, Roberts JL, Lance RS, et al.: Relationship between obesity and race in predicting adverse pathologic variables in patients undergoing radical prostatectomy. Urology. 2001; 58: 723-8.

26. Spangler E, Zeigler-Johnson CM, Coomes M, Malkowicz SB, Wein A, Rebbeck TR: Association of obesity with tumor characteristics and treatment failure of prostate cancer in African-American and European American men. J Urol. 2007; 178: 1939-44; discussion 1945.

27. Schymura MJ, Kahn AR, German RR, Hsieh MC, Cress RD, Finch $\mathrm{JL}$, et al.: Factors associated with initial treatment and survival for clinically localized prostate cancer: results from the CDC-NPCR Patterns of Care Study (PoC1). BMC Cancer. 2010; 10: 152.

28. Favorito LA, Nardi AC, Ronalsa M, Zequi SC, Sampaio FJ, Glina S: Epidemiologic study on penile cancer in Brazil. Int Braz J Urol. 2008; 34: 587-91; discussion 591-3.

29. Nardi AC, Zequi Sde C, Clark OA, Almeida JC, Glina S: Epidemiologic characteristics of renal cell carcinoma in Brazil. Int Braz J Urol. 2010; 36: 151-7; discussion 158.

Correspondence address:

Dr. Rodolfo Borges dos Reis

Rua João Gomes Rocha, 835/

Apto. 162, Jardim Irajá

Ribeirão Preto, SP, 14020-550, Brazil

Fax: + 5516 3602-2593

E-mail: rodolforeis@fmrp.usp.br

only less than 10\% of exposed urologists-patients, the study of Nardi et al. is reasonably balanced and seems to represent a reliable random sample of the target population.

Considering the routine use of serum PSA testing and screening programs, resulting in a significant stage migration and improvement in outcome for patients with PCa ( while some men depending on the public health system tend to have their treatment delayed), those under private practice tend to be over-tested and over-diagnosed due to a myriad of circumstances (including 
medical income), supporting the classic aphorism: "Too late or too soon?"

In the highlighted study the possibility of selection and lead-time biases should be emphasized - once careful assessment of every diagnostic and therapeutic step taken in the study patients is mandatory to ensure that no stage or grade migrations have occurred. Those in the public system may have limited access to diagnostic tests and screening. In this regard, many uncontrolled variables, especially pre-diagnosis exposure to PSA and DRE and the impact of university-level education of institutions, should ideally be considered and compared between groups, mainly in future studies.

While this provocative study should be read with caution due to the complexity of interpreting prostate cancer outcome data (making comparisons among different groups of patients receiving different treatments at different institutions and over different conditions fraught with very serious errors and fundamentally unreliable), it stimulates important reflections.

"What would be the equilibrium between over and under diagnosis in the private-public dichotomy of the Brazilian medical system?" "Were all the biopsies necessary and all cancers required treatment? Especially in the private system?"

In our risk-averse society, clinically insignificant cancers are indeed found with pros-

\section{EDITORIAL COMMENT}

Understanding how socioeconomic status affects early diagnosis, treatment plan and outcomes are pivotal to elaborate any long term public and private health care plan. Comprehensive data regarding epidemiology is extremely valuable.

Prostate cancer is the most common noncutaneous human malignancy and its epidemiology has been well reported in some parts of the World. Here at the United States, several publications and databases have been performed to better understanding this prevalent disease. From our institution, Byers et al. (1) demonstrated that low socio economic (SES) status is a risk factor for all- tate biopsy and over-treated. Survival and quality of life endpoints would make future studies stronger, pursuing better evidence to support and guide population-based preventive actions and health system improvement. "Are the patients in the compared groups different?" (reinforcing the hypothesis of selection bias). Or are they the same patients in different moments of the time-line and/or under different conditions?" (supporting the lead-time bias).

The Will Rogers phenomenon is a more obscure bias that is easily overlooked and that cannot be excluded in the development of the presented scenario represented by an apparent improvement in outcome for groups of patients with no actual improvement for any individual patient.

Dr. Leonardo Oliveira Reis
Department of Surgery (Urology)
State University of Campinas - UNICAMP
Hospital das Clinicas UNICAMP
20 andar, A2 - sala 108
R. Vital Brazil - 250
Cidade universitária Zeferino Vaz,
Distrito de Barão de Geraldo
Campinas, SP, Brasil
E-mail: reisleo@unicamp.br

cause mortality after a diagnosis of cancer, largely because of a later stage at diagnosis and different treatment options availability. CAPSURE (Cancer of the Prostate Strategic Urologic Research Endeavor), an American observational disease registry, was created in 1995 and since that several studies have been published on Prostate cancer epidemiology $(2,3)$.

Brazil has just become the world's sixth largest economy and only the state of Sao Paulo represents more than $1 / 3$ of Brazil's gross domestic product. Unfortunately social and health improvements haven't matched economy's improvement yet, and lack of disease epidemiologi- 
cal data remains an issue even at the richest state of the country. To the best of my knowledge, this is the first publication describing epidemiological feature and patterns of prostate cancer patient's care both in public and private institutions. The authors performed a cross sectional web based survey study to determine features and patterns of how prostate cancer has been treated and its implication in terms of diagnosis, treatment and outcomes. All SBU (Brazilian Urological Society) members from Sao Paulo state were invited to participate on the survey. Although only $10 \%$ of the members contributed with some data, almost 2000 patient's data were gathered and analyzed. Very interesting conclusions were made from the data such as patients attended at public institutions were more likely to have late stage disease.

I would like to congratulate the authors and the SBU-Sao Paulo for this project. It was a tremendous effort and so much important information was already obtained. The merits of this study are not only based on its conclusion, but mostly on the descriptive data collected that will be extremely useful to compare Sao Paulo state with other geographical areas and also to assess improvement in the health system within the state overtime. I encourage all the urologists to participate in upcoming surveys and make sure that SBU can count on every member's contribution and leads the research to better understand common urological conditions such as prostate cancer.

\section{REFERENCES}

1. Byers TE, Wolf HJ, Bauer KR, Bolick-Aldrich S, Chen VW, Finch $\mathrm{JL}$, et al.: The impact of socioeconomic status on survival after cancer in the United States : findings from the National Program of Cancer Registries Patterns of Care Study. Cancer. 2008; 113: 582-91.

2. Sadetsky N, Lubeck DP, Pasta DJ, Latini DM, DuChane J, Carroll PR: Insurance and quality of life in men with prostate cancer: data from the Cancer of the Prostate Strategic Urological Research Endeavor. BJU Int. 2008; 101: 691-7.

3. Moses KA, Paciorek AT, Penson DF, Carroll PR, Master VA: Impact of ethnicity on primary treatment choice and mortality in men with prostate cancer: data from CaPSURE. J Clin Oncol. 2010; 28: 1069-74.

Dr. Alexandre Pompeo and Dr. Wilson R. Molina Denver Health Medical Center Division of Urology-Surgery Department School of Medicine -University of Colorado E-mail:wilson.molina@dhha.org 